\title{
ENSINAR E APRENDER HISTÓRIA COM LIÇÕES E TESTES MOODLE
}

\author{
TEACHING AND LEARNING HISTORY LESSONS AND TESTS WITH MOODLE
}

Armando Augusto Oliveira ${ }^{1}$

\begin{abstract}
RESUMO: $O$ trabalho que se apresenta visa partilhar de forma resumida a experiência de utilização de um Ambiente Virtual de Aprendizagem (AVA) Moodle com cinco turmas de nono ano de escolaridade no ano letivo de 2009-2010. Recorrendo a lições e testes Moodle para o ensino e aprendizagem da disciplina de História em turmas do terceiro ciclo, registaram-se dados das suas implicações pedagógicas. A investigação efetuada recorreu a vários instrumentos de recolha de dados, entre os quais, registos do sistema Moodle, diários de bordo e questionários, cuja análise permitiu identificar potenciais aspetos justificativos sobre a perceção dos alunos. Seguindo um modelo sócio construtivista que potencia um papel mais ativo dos alunos no processo de ensino e aprendizagem efetua-se uma reflexão em torno da utilização das lições e testes Moodle e da propensão para utilização das Tecnologias da informação e comunicação (TIC) e das suas potencialidades pedagógicas.
\end{abstract}

Palavras-chave: História. Moodle. Lições. Testes. Ambiente Virtual de Aprendizagem.

\begin{abstract}
The work here presented intends to briefly share an experiment made concerning the use of a Moodle Virtual Learning Environment (VLE) with five ninth grade classes during the school year of 2009/2010. With the help of Moodle lessons and tests for History teaching and learning in elementary education classes, data were registered of their pedagogical implications. The investigation that took place used several data gathering instruments, among which lie the register system of Moodle itself, logbooks and questionnaires, whose analysis allowed the identification of potential justifications for the students ' perception. Following a socio-constructivist model, which potentiates a more active role of the students in the teaching and learning process, a reflection is made on the use of Moodle lessons and tests as well as on the tendency for the use of the Information and Computer Technologies (ICT) and their pedagogical potential.
\end{abstract}

Keywords: History. Moodle. Lessons. Tests. Virtual learning environment.

\footnotetext{
${ }^{1}$ Docente de História do Ensino Básico e Secundário, é licenciado pela Faculdade de Letras da Universidade do Porto, especialista em Informática Educacional e Mestre em Ciências da Educação. Tese sobre a aplicação do Moodle ao ensino e aprendizagem na Disciplina de História no ensino básico.
} 


\section{INTRODUÇÃO}

A internet é, nos dias de hoje, uma ferramenta primordial na promoção de práticas de literacia e comunicação que possibilita um novo relacionamento pedagógico potenciando uma nova aproximação a novos conteúdos e sua exploração bem como criação de comunidades de prática. Estas comunidades de prática no plano do e-learning com cenários pedagógicos em regime de blended learning (MARTYN, 2003), são potenciador de práticas auto-reflexivas e reformadoras de processos.

Reconhece-se assim, que o desenvolvimento das competências de literacia e comunicação nos novos media online se assume importante para o sucesso em muitas áreas da vida.

A introdução de Ambientes Virtuais de Aprendizagem (AVA) (JONASSEN, 2007) perspetivados como ferramentas cognitivas, poderá promover, com a utilização das lições e testes Moodle, a integração de um projecto educativo construtivista assumido, enquadrando os alunos em actividades verdadeiramente significativas que impliquem cada aluno na gestão do seu processo educativo (VALADARES E MOREIRA, 2009).

É, pois, a internet como meio de comunicação, que altera profundamente a comunicação no processo formal de educação e entre o trio conceptual professores, alunos e conteúdo (GARRISON; TERRY, 2003).

A integração das tecnologias na educação torna essencial, o desenvolvimento integral da formação dos alunos de hoje, confrontados com um mercado de trabalho em constante mudança e transformação, sendo pois, prioritário trabalhar as competências mas também desenvolver um espírito aberto, flexível e capaz de se adaptar para evoluir (CRUZ, 2008). São os nossos alunos nativos digitais, indivíduos que consumem imensa informação muito rapidamente, de inúmeras fontes, que anseiam por respostas e feedback constantes (DOWNES, 2005). É para estes que a motivação é cada vez menor para as aulas tradicionais e maior para as tecnologias informáticas (VILLATE, 2005).

Estes novos alunos que Marc Prensky (2011) designou por nativos digitais, representam a primeira geração que cresceu com a singularidade de estar 
imersa em tecnologia digital como nenhuma outra. Esta tecnologia faz parte da vida deles e essa ubiquidade aponta para existência de novos padrões de pensamento. Por oposição a estes nativos digitais que falam a linguagem dos computadores estão os imigrantes digitais, incluindo nestes muitos professores que estão a ensinar uma geração que fala como que outra língua. Estes nativos digitais parecem preferir outros contextos de aprendizagem com processos paralelos e multitarefa e preferem apreciar gráficos antes do texto, em vez do oposto. Preferem também acesso aleatório (como hipertexto) e parecem funcionar melhor quando ligados em rede. Para o mesmo autor, os educadores têm mesmo de adaptar metodologias digitais aos seus conteúdos, incluindo a História. Apesar de profundamente favoráveis ao uso da tecnologia na sala de aula para ensinar história não esquecemos o essencial: tratar de informação e utilização de fontes; a compreensão histórica e a comunicação em história. A natureza estruturante e o carácter globalizante da História, legitimam uma formação exigente dos professores, e uma prática docente atual que prepare os alunos para a promoção de competências gerais, transversais e específicas, que combata o absentismo cívico e promova cidadãos com uma consciência social aberta, democrática e participativa.

Estamos cientes dos limites do uso da tecnologia. Citamos Nicholas Carr (2008) que relembra a sombria profecia de Kubrick no filme 2001: "That's the essence of Kubrick's dark prophecy: as we come to rely on computers to mediate our understanding of the world, it is our own intelligence that flattens into artificial intelligence". ${ }^{2}$

No entanto, porque falamos de um trabalho aplicado a discentes de ensino tradicional, temos de abordar o b-learning como um modo de aprender que combina o ensino presencial com a tecnologia não presencial ?]"which combines face-to-face and virtual learning" (COATEN, 2003). Singh (2003) defende o $b$ learning como um processo contínuo, que mistura vários tipos de atividades como aulas em presença, e-learning e aprendizagem ao ritmo de cada um. Isto é, uma conjugação do ensino tradicional, com o treino ou comunicação

\footnotetext{
2 "Essa é a essência da sombria profecia de Kubrick: como chegamos a contar com computadores para mediar nossa compreensão do mundo, é a nossa própria inteligência que se achata em inteligência artificial."
} 
síncronos, estudo individual assíncrono e treino estruturado e efetivo, com a ajuda de um tutor ou colega experiente.

A intenção de alargar a escolaridade um pouco por todo o mundo para os dezoito anos, torna pertinente toda a problemática do ensino tradicional, elearning e b-learning que ganham novos contornos no que diz respeito aos processos, métodos e relações pedagógicas num ensino obrigatório que alarga o conceito de aluno.

\section{Metodologia}

Seguimos neste trabalho uma abordagem TPACK (Technological Pedagogical Content Knowledge), quadro teórico que procura atingir uma visão integrada das três bases de conhecimento. Mais do que uma visão integrada conjugam-se as três esferas de conhecimento em novos tipos de conhecimento que estão na interseção. Considerando $P$ e $C$ juntos temos conhecimento pedagógico do conteúdo (PCK), a ideia inicial de Shulman $(1987,1988)$ de conhecimento da pedagogia que é aplicável ao ensino de conteúdos específicos. Da mesma forma, considerando-se $\mathrm{T}$ e $\mathrm{C}$ tomados em conjunto, temos conhecimento do conteúdo tecnológico (TCK), o conhecimento da relação entre tecnologia e conteúdo. No cruzamento da T e P, está o Conhecimento Pedagógico Tecnológico (TPK), que enfatiza a existência, componentes e capacidades de várias tecnologias, como são utilizados nas configurações de ensino e aprendizagem. Para um professor de História preocupado em não deixar escapar a motivação dos seus alunos envoltos numa teia de tentações digitais, a reflexão dos pressupostos desta referência teórica parece importante.

O Conhecimento Pedagógico de Conteúdo Tecnológico (TPACK), tenta capturar algumas das qualidades essenciais de conhecimento exigido pelos professores para a integração da tecnologia no seu ensino, ao discursar na natureza complexa e multifacetada e situada do conhecimento do professor. No centro do quadro TPACK, está a complexa interação de três formas principais de conhecimento: Conteúdo (CK), Pedagogia (PK), e Tecnologia (TK), (Ver Figura I). 


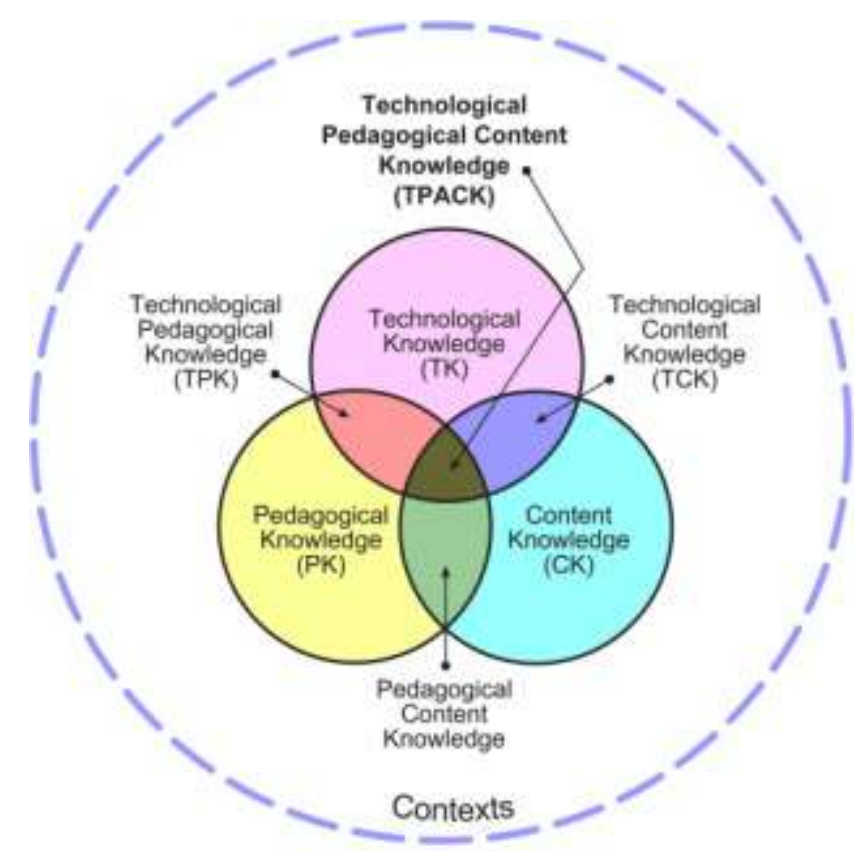

Figura I - Conhecimento Pedagógico de Conteúdo Tecnológico (TPACK) ${ }^{3}$

A integração de tecnologia eficaz para a pedagogia em torno de um assunto específico requer sensibilidade em desenvolvimento para o relacionamento dinâmico, transacional entre os três componentes. Um professor capaz de interligar essas relações apresenta uma forma de conhecimento diferente e maior do que o conhecimento de um perito disciplinar.

Construiu-se assim um espaço virtual num sistema Moodle com o objetivo de ser um ponto de apoio da disciplina de História, apontando o seu objeto de estudo para dois eixos fundamentais, a saber:

- $\quad$ Como se desenvolveu o processo ensino-aprendizagem com recurso a lições e testes Moodle?

- Qual a perceção que os alunos têm da realização das lições e testes Moodle no ensino da disciplina História?

O percurso de trabalho seguiu uma orientação construtivista (JONASSEN, PECK; WILSON, 1999) preconizando a interação dos estudantes na construção do conhecimento.

\footnotetext{
${ }^{3}$ Fonte:http://tpack.org/
} 
Foram utilizados diários de bordo e inquéritos online (LESSARD-HÉBERT, 1996) que permitiram avaliar o impacto da utilização do AVA junto dos alunos, numa análise qualitativa dos resultados (BOGDAN, 1994).

\section{Projeto}

Durante o processo de apresentação do projeto, no início do ano, solicitouse o preenchimento de um inquérito de literacia informática, anónimo, já disponível na plataforma.

Responderam ao inquérito 70 alunos, de 121 no total, 74 raparigas e 47 rapazes. Este inquérito permitiu apurar que a grande maioria (94,2\%) tinha computador em casa e $47,1 \%$ considerava-o um instrumento de lazer, mas todos partilhavam a visão de que o computador é um instrumento de trabalho. Só $5 \%$ dos alunos indicou não possuir acesso à internet em casa.

A utilização do computador continua a revelar as preferências pelo jogar (30\%) envio e receção de mensagens, (16\%). A realização de trabalhos é apontada como preferência secundária com 12\%.

A disciplina Moodle foi desenvolvida com formato tópico, dividindo os conteúdos das lições e testes distribuídos por unidades temáticas da disciplina. Cada tópico disponibilizado pressupunha a leitura de questões orientadoras, a realização de uma lição, um mini teste e um teste.

Regista-se a preocupação na elaboração das atividades acompanhando o programa da disciplina. As lições e testes foram criados tendo em conta uma ligação direta entre o manual e as planificações do grupo disciplinar. Anteciparam-se momentos de aula com planificação e aplicação de sequências de atividades de ensino/aprendizagem, como aclarados por Zabala (1998,2001). Assumiu-se neste estudo o papel do aluno ativo que interage com materiais digitais (MORGAN, 1995), disponibilizando-Ihe via AVA, com objetivo específico e ponderado, lições e testes Moodle, que o implicassem e o responsabilizassem realmente, na construção do seu próprio estudo e conhecimento. Importante é, pois, criar condições para que os alunos possam aprender, concebendo 
atividades que representem um desafio a resolver. As lições e testes Moodle tiveram também esse propósito.

A figura seguinte (fig. II) mostra a sequência de tópico 1. No total foram disponibilizadas ao longo de todo o ano letivo 1 teste diagnóstico inicial, 9 lições, 9 mini-testes formativos (áudio testes), e 9 testes, perfazendo 28 atividades.

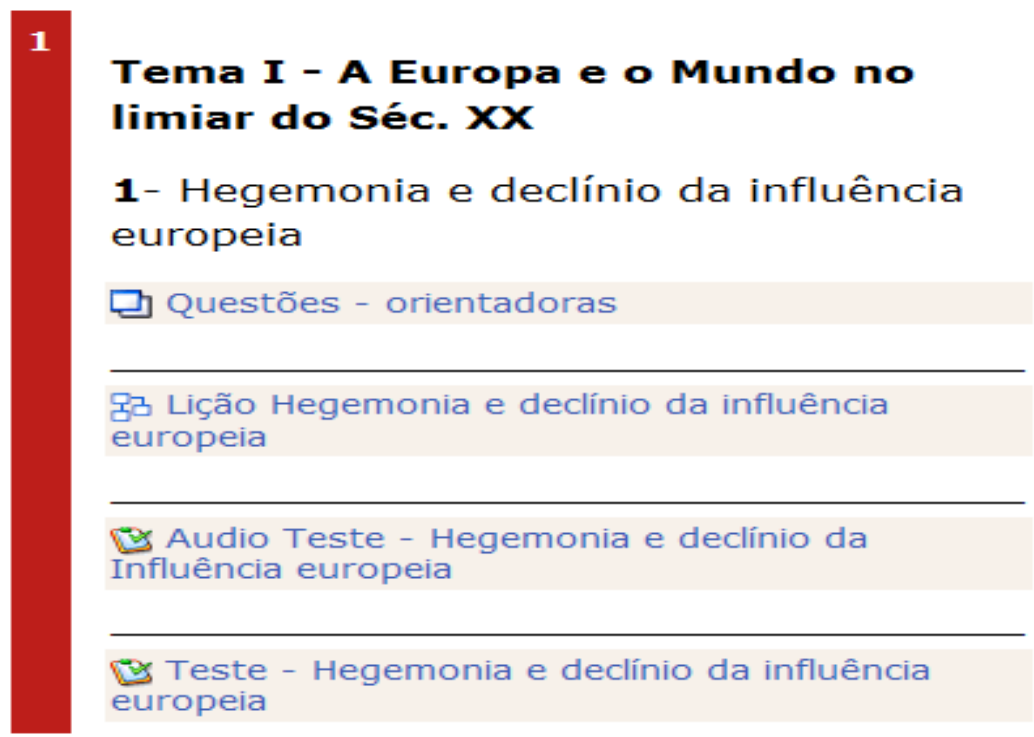

FIgURA II - SEQUÊNCIA DE TÓPICO 1.

\section{As LIÇões}

A Lição Moodle exibe um conjunto de páginas com conteúdos pedagógicos, seguindo uma sequência mais ou menos não linear, que é determinada em função das respostas do aluno. A configuração mais simples, linear, pode ser traduzida da seguinte forma: o aluno examina o conteúdo disponível e responde a uma pergunta, se a sua resposta estiver correta avança para a pergunta seguinte. Se errar tem de repetir a pergunta errada (ver fig. III). 


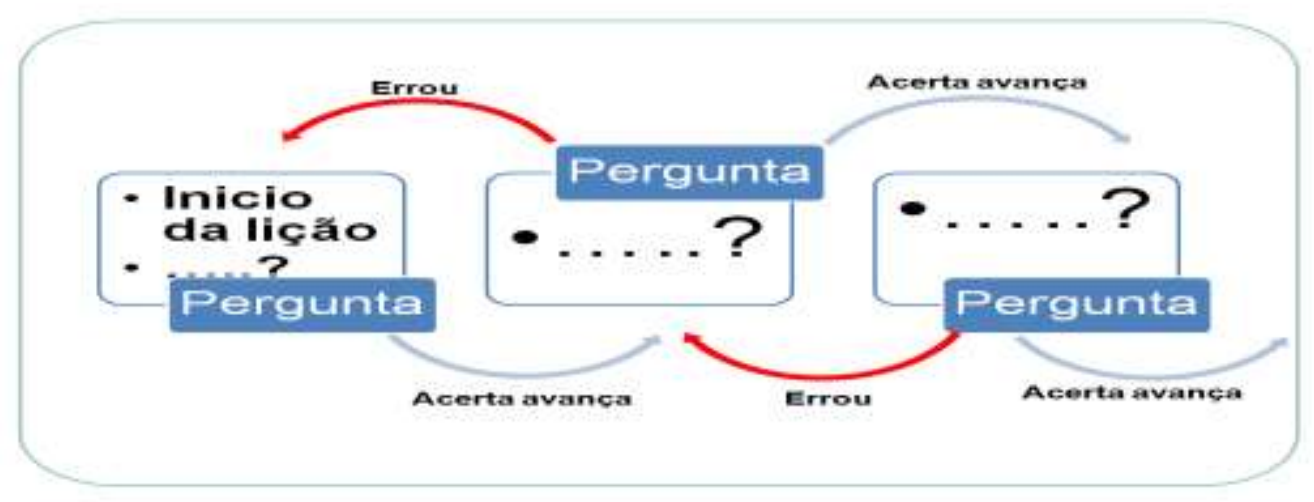

\section{FIGURA III- ESQUEMA DE LIÇÃo LINEAR}

Num percurso de lição não linear (figura IV) a sequência de visualização das perguntas pode variar de acordo com as respostas de cada aluno e permite adaptar o percurso de aprendizagem de cada aluno ao nível de conhecimentos demonstrados.

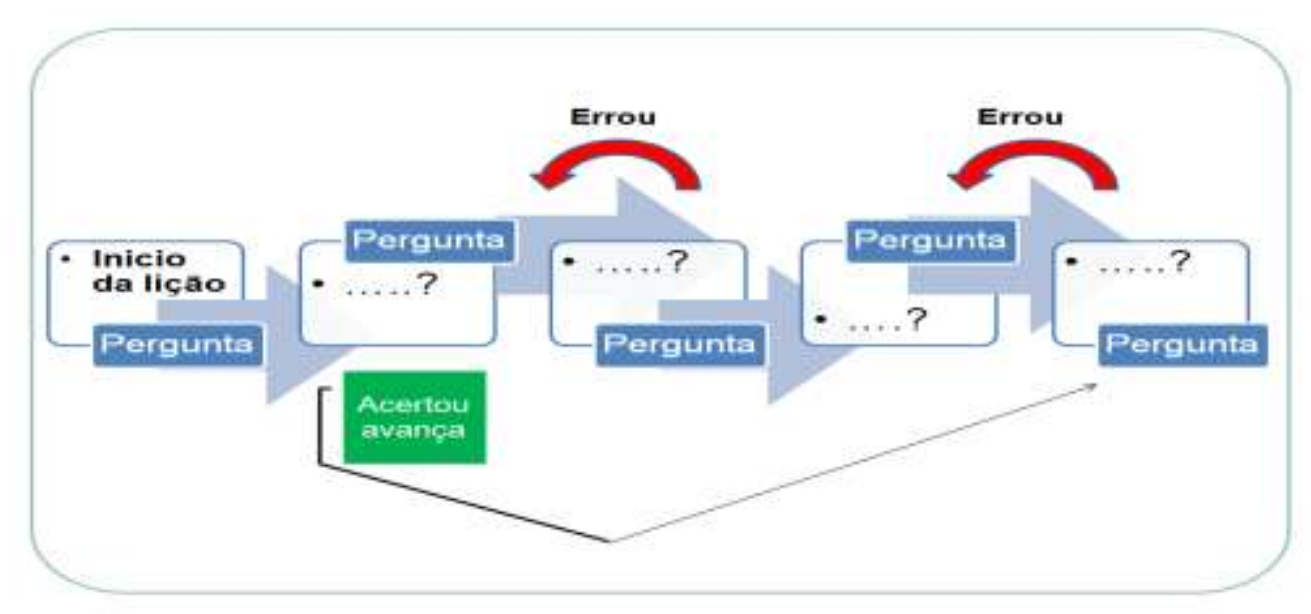

FIGURA IV - ESQUEMA DE LIÇÃo NÃo LINEAR

Seguiu-se neste projeto a lição linear, mas reconhecemos, no entanto, as vantagens de uma lição construída seguindo um percurso não linear que fomenta a estruturação de conteúdo com patamares de apoio e remediação, quando necessário, ou disponibiliza atividades de enriquecimento ou de aprofundamento, quando apropriado. 
As lições digitais Moodle potenciam a envolvência dos alunos com os conteúdos já aprendidos ou tornam viável a aquisição e/ou consolidação de aprendizagens, desenvolvendo competências fundamentais. Na elaboração das lições teve-se em conta uma fase de conceptualização da sequência lógica das questões a colocar, tal como o ajustamento dos conteúdos ao tipo de questão eventualmente mais adequado (Zabala, 1991).

Aceita-se a lição como uma atividade motivacional que, em simultâneo, tem implícito o apelo a um papel mais interventivo dos alunos na ótica de se assumirem como agentes ativos. Procurou-se disponibilizar questões simples e complexas, facultar a exploração de fontes históricas diversificadas, fornecer novas informações, fomentar pesquisa, enfim, proporcionar a vivência de avanços e recuos na construção do seu conhecimento em prol do sucesso pessoal. Proporcionou-se momentos de construção do conhecimento, estes, considerados essenciais para a perceção da necessidade de trabalho e empenho para o êxito escolar de alunos digitais.

\section{Testes}

O AVA Moodle permite criar diversos e diferentes tipos de questões, conceber testes com perguntas aleatórias e permitir várias tentativas de resposta ao aluno. Os muitos constrangimentos do ensino presencial são diminuídos com a capacidade de obter um registo do cálculo automático e a criação de inúmeros testes de perguntas aleatórias, por exemplo, sempre disponíveis, recorrendo a uma bateria de testes criados.

A possibilidade de proporcionar feedback ao aluno acerca do seu desempenho é, obviamente, um dos aspetos críticos em ambientes de aprendizagem, e mesmo com testes simples de escolha múltipla é possível obter informação relevante. Isto constitui uma excelente maneira de possibilitar ao aprendente uma autoavaliação da sua performance e permitir o aperfeiçoamento. Da mesma forma os testes Moodle possibilitam avaliar o cumprimento de metas de aprendizagem e objetivos, ou mesmo, aferir o conhecimento adquirido, a compreensão, aplicação e análise, numa perspetiva 
de Bloom, mesmo na versão revista por Andrew Churches ${ }^{4}$ e publicada no site Eduteka, sob o título Bloom's Digital Taxonomy. Esta utilização de um AVA que faculta interatividade, remete para a renovação de espaços e tempos de ensino e aprendizagem para os alunos digitais (ROLLINS, 2010).

Neste projeto geraram-se dois tipos de testes Moodle. Um primeiro designado de áudio teste (ver Figura V) consistia num ficheiro áudio de curta duração ${ }^{5}$ que reproduzia oito questões do tipo escolha múltipla com resposta embebida. O aluno, no áudio teste, deveria escutar com atenção as questões e ir respondendo no teste às questões colocadas.

Estes ficheiros audio foram produzidos com o software Audacity ${ }^{6}$, de código fonte aberto, para edição de áudio digital. O programa Audacity é um software livre e gratuito desenvolvido por um grupo de voluntários e distribuído sob a GNU General Public License(GPL).

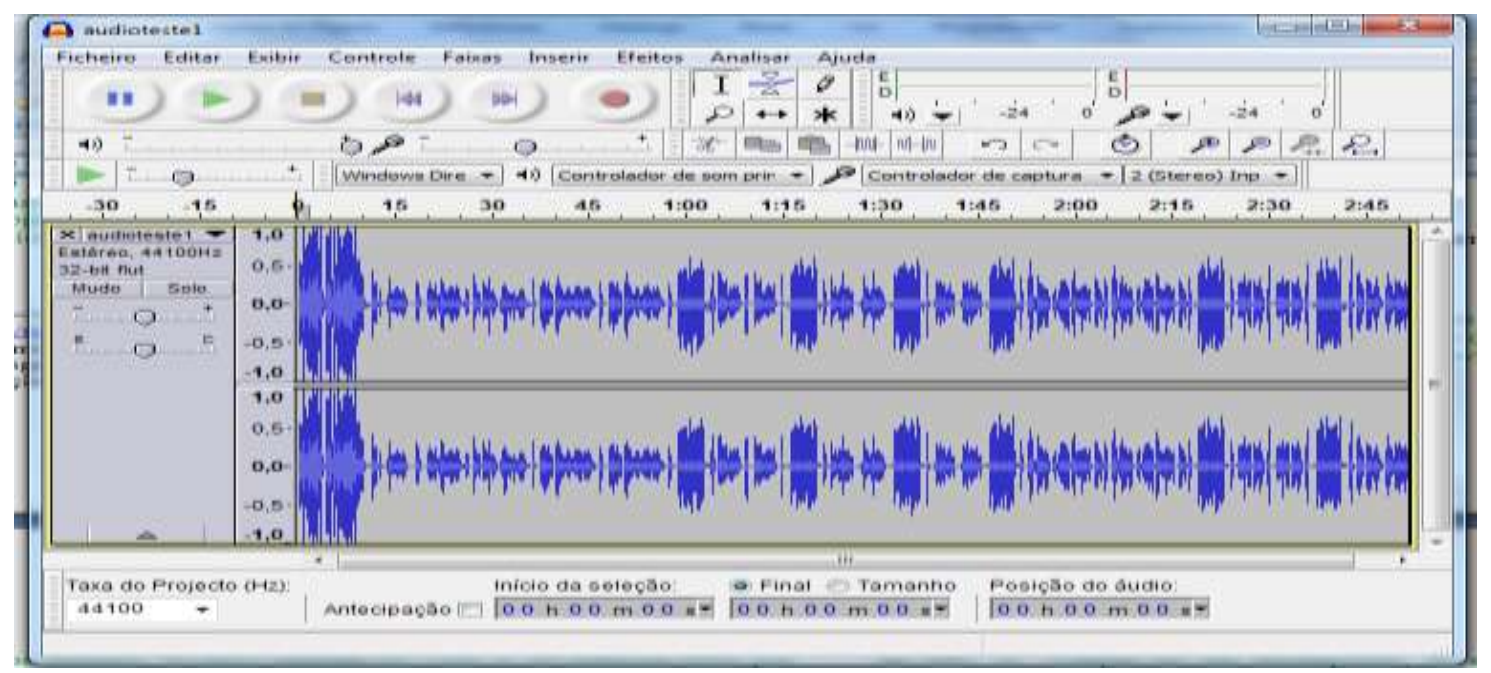

FigURA V - CAPTURA DE ECRÃ do PROGRAMA AUDACITY.

O momento de avaliação. que se queria formativo. com os aúdio testes, foi disponibilizado ao longo da aprendizagem, permitindo ao aluno apreciar os progressos, ou não, mas também ao professor identificar pontos de dificuldades de aprendizagem. (ASTOLFI, 1997).

\footnotetext{
${ }^{4}$ http://www.eduteka.org/TaxonomiaBloomDigital.php

5 Seguimos a taxonomia provisória criada no âmbito do Projecto "Implicações Pedagógicas da Utilização de Podcasts em Blended-Learning" (Carvalho et al, 2009),

${ }^{6}$ http://audacity. sourceforge.net/?lang=pt
} 
O segundo tipo de teste era um clássico teste de dez questões de escolha múltipla. Cada tópico era iniciado com um conjunto de questões interrogativas para cada unidade de estudo, de forma a permitir o direccionamento do estudo do aluno pelos conteúdos abordados.

Ambicionava-se que, na medida do possível, fossem bastante perceptiveís para o aluno dois grandes objectvos, ter prática do que se aprendeu em contexto de sala de aula e preparar para novas informações apresentadas, esbatendo a pressão sentida pelos alunos aquando da realização das fichas de avaliação (figura VI).

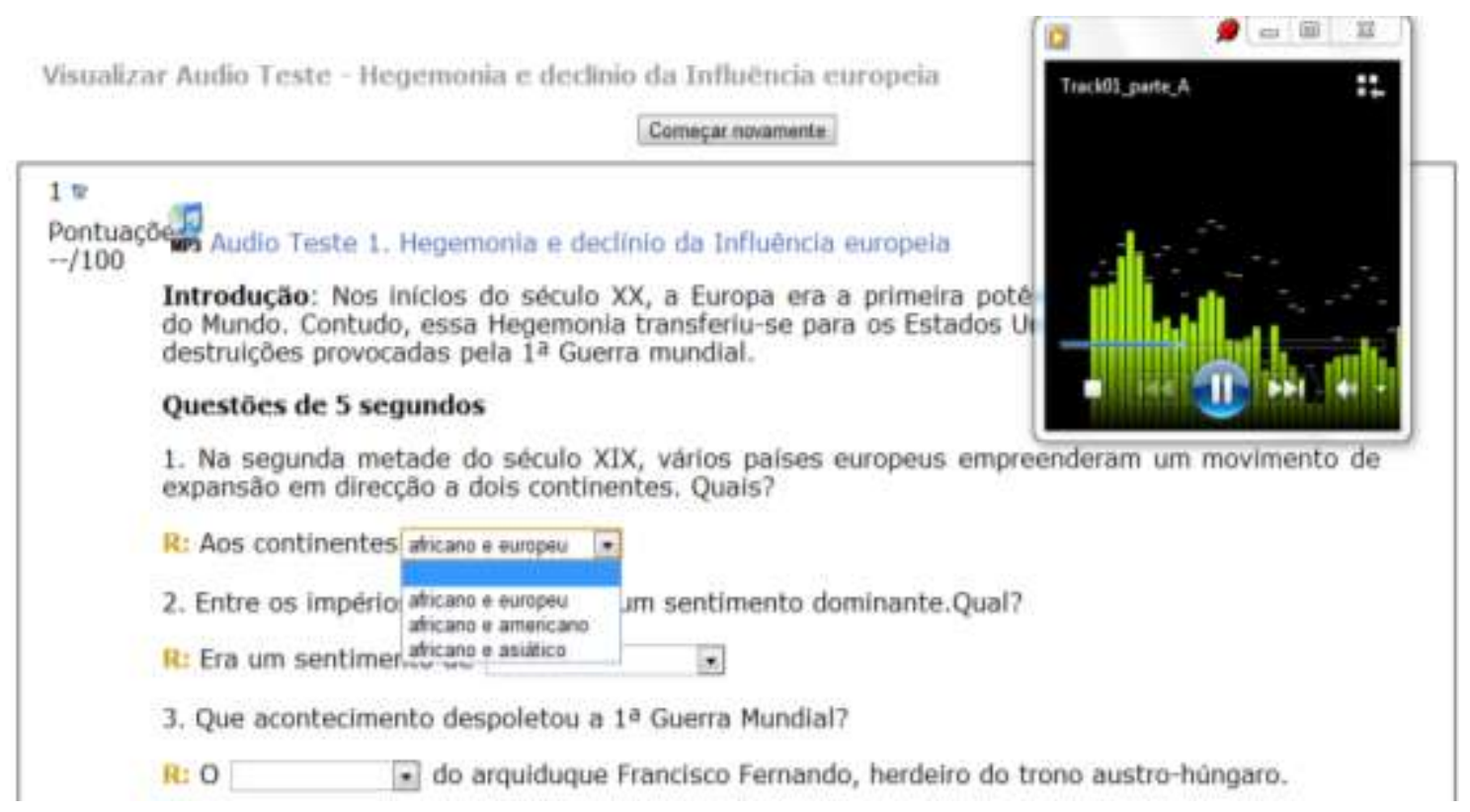

Figura VI - CAPTURA de ECRÃ PARCial do Mini teste (ÁUdio teSTe 1).

\section{Recolha de Dados e Análise de Dados}

Neste artigo, por razões que se prendem com os limites de extensão do mesmo, apenas focaremos os dados recolhidos no questionário final. $\mathrm{Na}$ elaboração dos questionários tivemos em conta a revisão de literatura sobre estudos similares. Tivemos também em conta as advertências feitas por Hill e Hill (2005) e Moreira (2004) relativas à construção dos questionários. 
60 apontava para que a qualidade do ensino que um aluno recebe é responsável por apenas cerca de $10 \%$ na variação no seu desempenho, deve ser profundamente contestado. Estamos convictos, tal como Marzano (2008), que um professor individualmente pode ter um efeito poderoso nos seus alunos, mesmo que a escola no seu todo não o tenha. Para isso, acreditamos que a diferença pode estar na implantação de práticas eficazes.

Proporcionar feedback num trabalho ou lição de casa serve, ou deve servir, para melhorar o desempenho do aluno. As lições e teste Moodle para além de facilitarem esse feedback automático aliam-se a outra vantagem, a de se poderem constituir num trabalho de casa que fornece apoio no processo de realização da atividade. Ou seja, responsabiliza os alunos por compromissos, sistematiza aprendizagens significativas e ajuda a recuperar eventuais dificuldades. Assim, setenta e um por cento dos alunos considerou que as lições e testes Moodle melhoraram a qualidade do estudo na disciplina de História.

O gráfico seguinte (gráfico II) permite destacar a vontade dos alunos de verem repetidos noutras disciplinas projetos de trabalho idênticos. Da mesma forma é relevante a consciência do valor da internet assumido como factor essencial em trabalhos deste tipo e a falta do factor presencial do professor.

5. Seria importante que todas as disciplinas tivessem um site deste género.

4. O facto de precisar de ter acesso à internet para aceder ao site foi para mim uma limitação.

3. Ao aceder ao site senti falta de poder fazer perguntas ao professor

2. Permitiram desenvolver competências de estudo

1. Aumentaram a minha responsabilidade perante o estudo

Discordo totalmente

- Concordo

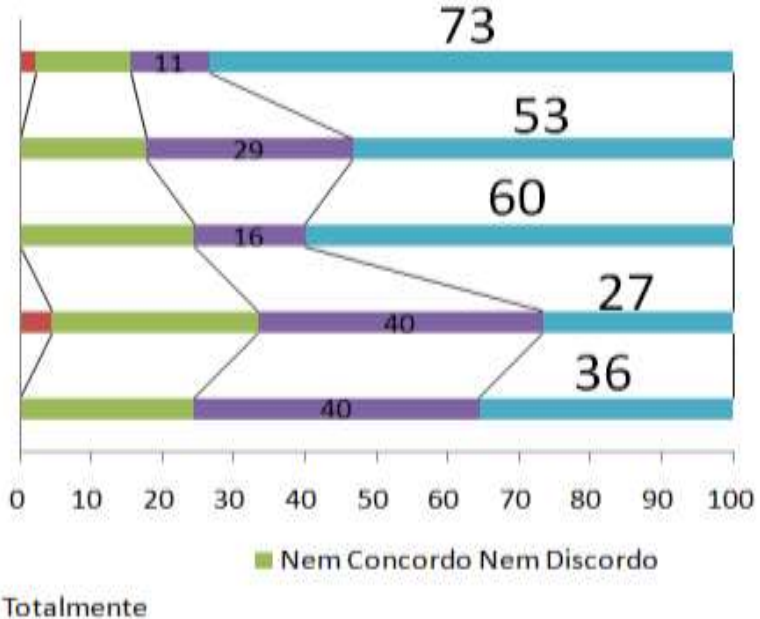

Concordo Totalmente

GrÁFICO II - DADos RELATIVos À diMENSÃo MOTIVAÇÃo E RESPONSABILIDADE PERANTE O ESTUDO.

Do próximo gráfico (gráfico III) perspetivou-se a valorização da componente de e-learning do projeto. Recorde-se que estamos a falar de um grupo que está na faixa etária dos 13-16, muitas vezes não apresentando as 
características típicas daquilo que se denomina por o aluno do ensino à distância (Santos, 2000). No entanto, nos resultados obtidos, muitas das características do jovem adolescente que adere a um projeto de ensino aprendizagem à distância como motivação, responsabilidade e capacidade para a autoaprendizagem, estiveram presentes.

Assumiu-se também o carácter "avaliativo" do processo de aprendizagem na sua dimensão que designaríamos de estudo/autoestudo, com 91\% dos alunos a referir que, saber que podia realizar lições e testes com classificação fez com que se esforçassem mais (ver gráfico III).

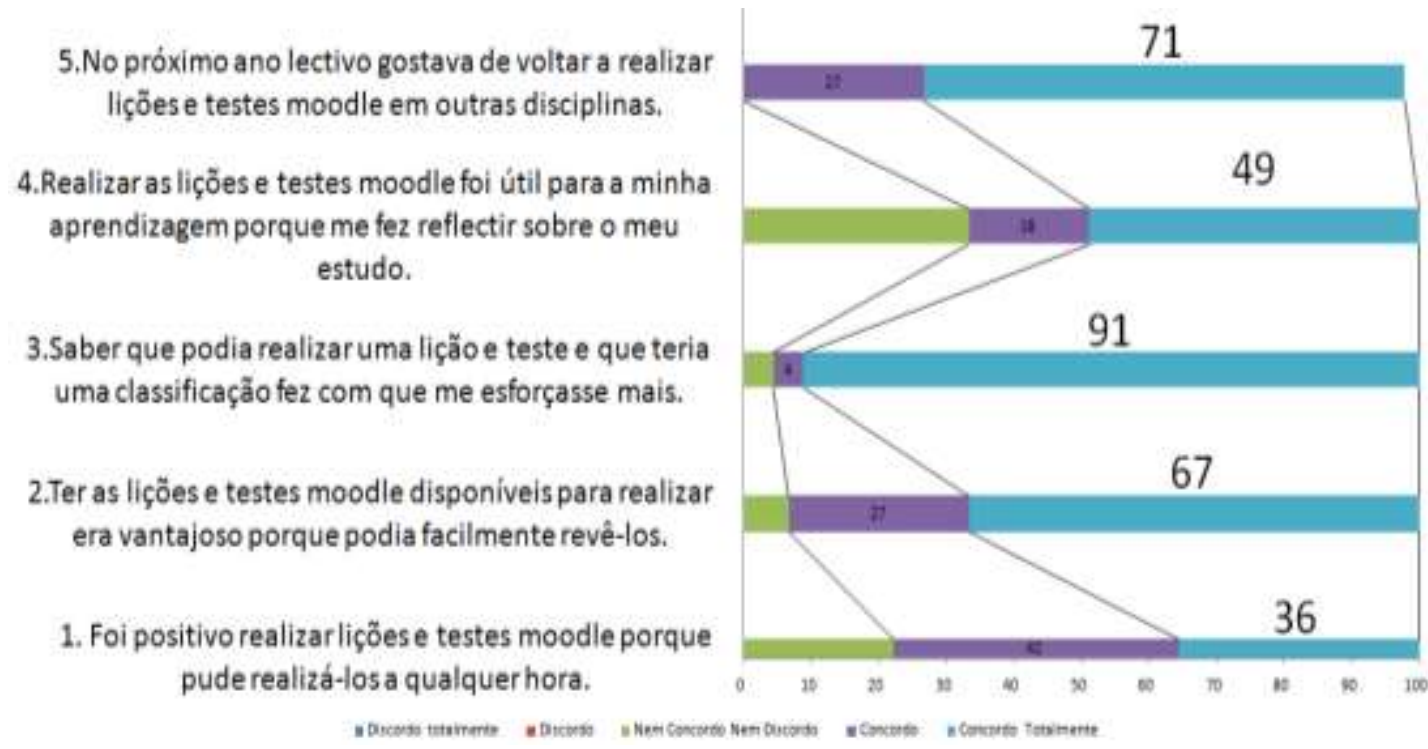

\section{GrÁFICO III - DADOS RELATIVOS À DIMENSÃo UTILIDADE, PREFERÊNCIA E DISPONIBILIDADE NO TEMPO E ESPAÇO.}

A faculdade disponibilizada de realizar as lições e testes prolongou o estudo para além dos limites do dia letivo ao mesmo tempo que permitiu uma reflexão sobre a aprendizagem numa dimensão de responsabilidade perante o estudo. Registou-se também a vontade dos alunos em realizar mais lições e testes Moodle no próximo ano letivo tanto à disciplina de História como a outras disciplinas, naquilo a que designamos por dimensão prospetiva do projeto.

A perceção dos alunos sobre a utilização dos testes e lições foi valorizada também através de duas questões abertas e permitiu obter dados que foram organizados, possibilitando, via análise simples de conteúdo, a construção da tabela seguinte (Figura VII). 


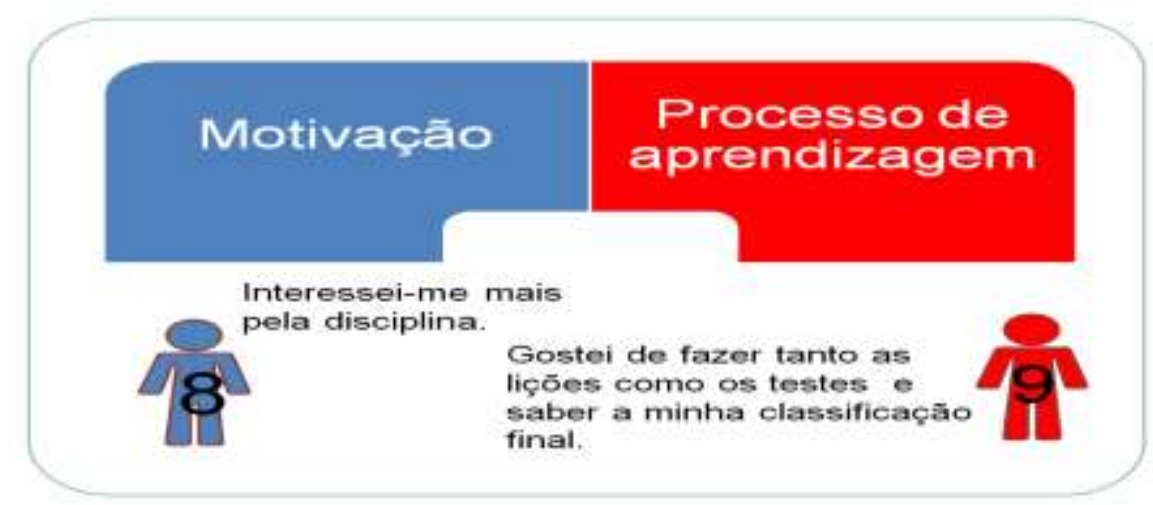

\section{FIgURA VII - CATEgORIZAÇÃo DAS RESPOSTAS dOS ALUNOS ÀS QUESTÕES ABERTAS: APROVEITA O ESPAÇO SEGUINTE PARA DIZER ALGO MAIS SOBRE A TUA EXPERIÊNCIA COM A UTILIZAÇÃo dAS LIÇÕES / ÁUdIO TESTES E TESTES MOODLE. CRÍtICAS, SUgeSTÕeS... ESCREVE À VONTADE.}

Uma categorização das respostas dos alunos permitiu uma análise do conteúdo das mesmas, tendo sido recolhidas citações das palavras destes para as ilustrar. Das opiniões dos alunos, apuraram-se duas áreas, categorias, influenciadas pelo tipo de trabalho realizado na plataforma: a motivação e o processo de aprendizagem.

As lições e testes espelharam uma evolução lógica e gradual do trabalho ao longo do ano tentando-se que o aluno reforçasse os seus saberes. Assim, potenciaram no aluno a noção de que necessitava de estar mais atento/concentrado nas aulas e estudar mais ou premiava o empenho refletido no resultado obtido. Por conseguinte, mais do que interpretarmos os resultados deste trabalho como questões relativas a conhecimentos, estão subjacentes atitudes e valores referentes aos alunos e à sua atitude perante o processo de ensino e aprendizagem.

A introdução de novas tecnologias no processo de ensino aprendizagem foi reconhecida como elemento catalisador de motivação no caso em estudo, um ambiente virtual disciplinar. Os alunos admitiram que passaram a interessar-se mais pela disciplina. Como sugestões e indo ao encontro do já apontado nas questões fechadas, sugeriram a continuação do trabalho no ano seguinte com o alargamento a outras disciplinas. Já Oliveira e Cardoso (2008) destacavam a preferência por atividades não tradicionais, no que diz respeito ao uso da plataforma Moodle neste mesmo nível de escolaridade. 


\section{Considerações finais}

Em prospetiva, equaciona-se alargar a aplicação da investigação quer ao nível disciplinar, quer ao nível de outras áreas relacionadas com o ensino e formação que podem ser objeto de atuação do ambiente de aprendizagem Moodle. Numa altura em que se difundem a criação de tutorias digitais, aplicadas a várias áreas, veja-se o projeto Khan Academy, ${ }^{7}$ talvez seja o momento de aproveitar o potencial tecnológico hoje ao dispor das escolas, através da disponibilização de conteúdos educativos digitais, para responder ao desafio, que também se adivinha, de integrar estas medidas no objetivo de garantir o cumprimento da escolaridade obrigatória de doze anos.

Por outro lado, a recente versão Moodle 2.0 traz consigo novidades a nível da possibilidade de condicionamento de atividades, ou seja, é possível definir os pré-requisitos de uma atividade. Pode-se agora condicionar o avanço do aluno nas atividades em função do resultado que tiver nas atividades anteriores. Esta característica potencia novas áreas de estudos, de dedicação e cumprimento de tarefas num percurso escolar, em que lições e testes só ficam disponíveis depois de cumprido o condicionamento, por exemplo, de uma data, classificação ou progresso.

Justifica-se sempre a necessidade urgente de potenciar as vantagens do acesso à internet com propósitos educativos. Aproveitar a utilização da internet não simplesmente no que se pode constituir como um repositório, como fonte de recursos, mas como um espaço de interatividade e de estudo ativo e participativo.

A utilização de lições e testes Moodle disponíveis online em horário não escolar, poderá permitir intensificar a dimensão do estudo como prolongamento da atividade escolar e ao mesmo tempo, reforçar o auto-estudo e a autoaprendizagem. Estamos convictos que com a disponibilização das lições e testes se fomentou o trabalho autónomo no ensino da História, permitindo, como refere Santos (1999), promover conhecimento transformador, regenerando alunos em agentes transformadores do seu próprio conhecimento, e promovendo até a

\footnotetext{
7 http://www.khanacademy.org/
} 
diminuição do papel de centralidade que as aulas tradicionais muitas vezes impõem.

O conhecimento histórico, tal como todas as outras áreas do conhecimento, está em profunda e constante mudança. Esta consciência e a capacidade de adaptação a essa realidade é uma das valências essenciais da História. Numa sociedade mergulhada em informação, exige-se que quem ensina História, saiba o que fazer com essa informação e que quem aprende, seja preparado para exercer uma cidadania ativa.

\section{Referências}

ASTOLFI, J. P. L'erreur, un outil pour enseigner. Paris: ESF éditeur.

BOGDAN, R.; BIKLEN, S.(1994). Investigação qualitativa e educação. Uma introdução à teoria e aos métodos. Porto: Porto Editora, 2009.

CARVAlHO, A. A.; AGUIAR, C.; SANTOS, H.; OliveiRA, L.; MARQUES, A. Podcasts in higher education: students' and lecturers' perspectives. Proceedings of the 9th WCCE IFIP World Conference on Computers in Education, Bento Gonçalves, RS, Brasil, 2009.

CARR, N. Is Google Making Us Stupid? Disponível em:

http://www.theatlantic.com/magazine/archive/2008/07/is-google-making-usstupid/6868/. 2008. Acesso em 18/06/2012.

COATEN, N. Blended e-learning. Disponível em:

http://www.educaWeb.com/esp/servicios/monografico/formacionvirtual/1181076 .asp 2003. Acesso em 18/06/2012.

CHURCHES, A. Bloom's Digital Taxonomy. Disponível em:

http://edorigami.wikispaces.com/file/view/bloom's+Digital+taxonomy+v3.01.pdf . 2009. Acesso em 18/06/2012.

CRUZ, S. Blogue, Youtube, Flickr e Delicious: Software Social. In CARVALHO, A. A. (Org.). Manual de Ferramentas Web 2.0 para Professores. Lisboa: DGIDC, Ministério da educação, 2008.

DOWNES, S. E-learning 2.0. Disponível em: http://www.downes.ca/post/31741 2005. Acesso em 18/06/2012.

GARRISON, R.; A. TERRY. E-Learning in the 21st Century: A Framework for Research and Practice. Nova Iorque: Routledge, 2003.

HILL, M.; HILL A. Investigação por Questionário. 2 ed., Lisboa: Edições Sílabo, 2005.

JONASSEN, D. H.; PECK, K. L.; WILSON, B. G. Learning with Technology: A Constructivist Perspective. Columbus, OH: Prentice Hall, 1999. 
JONASSEN, D.H. Computadores ferramentas cognitivas. Desenvolver o pensamento crítico nas escolas. Porto: Porto Editora, 2007

LESSARD-HÉBERT, M. Pesquisa em educação. Lisboa: Instituto Piaget, 1996.

MARTYN, M. The Hybrid Online Model: Good Practice. A hybrid approach to online learning offers important lessons for institutions entering the online arena. 2003. Disponível em: http://www.educause.edu/ir/library/pdf/EQM0313.pdf Acesso em $18 / 06 / 2012$.

MARZANO, R. J.; PICKERING, D. J.; POLLOCK, J. E. Ensino que funciona: estratégias baseadas em evidências para melhorar o desempenho dos alunos. Porto Alegre: Artmed, 2008.

MOREIRA, J. Questionários: teoria e prática. Coimbra: Livraria Almedina, 2004. MORGAN, A. Student learning and students' experiences. Research, theory and practice. In: LOCKWOOD F. (Org.). Open and Distance Learning Today .London: Routledge, 1995.

PRENSKY, M. Do They Really Think Differently? In Digital Natives, Digital Immigrants, Part II: Published in On the Horizon. NCB University Press, v.9, n.6, Dec. 2001.

OLIVEIRA, A.;CARDOSO, E. Boas práticas com Moodle no ensino da História. Caldas da Rainha: Livro de Actas. Caldas Moodle `08. Comunidades de aprendizagem Moodle. Associação Portuguesa de Telemática Educativa, 2008.

ROLLINS, M. J. Moodle and Bloom's Taxonomy. E-TeachUK 2010. Disponível em http://muppetmasteruk.blogspot.com/2010/05/moodle-and-bloomstaxonomy.html Acesso em 18/06/2012.

SÁ, J. Renovar as práticas no $1^{\circ}$ Ciclo pela via da Ciência da Natureza. Porto: Porto Editora, 1994.

SANTOS, A. Ensino a distância \& Tecnologias de Informação. Lousã: Editora Lidel, 2000.

SANTOS, M. Desafios pedagógicos para o século XXI. Biblioteca do Educador. Lisboa: Livros Horizonte, 1999.

SHULMAN, L.; GROSSMAN, P. The Intern Teacher Casebook. San Francisco, CA: Far Wets Laboratory for Educational Research and Development, 1988.

SHULMAN, L. S. Knowledge and Teaching: Foundations of the New Reform. Harvard Educational Review, v.57, n.1, 1-22, 1998.

SINGH, H. Building Effective Blended Learning Programs. Educational Technology, v.43, n.6, p.51-54. 2003. Disponível em:

http://www.faculty.english.ttu.edu/rice/blended-learning.pdf Acesso em $18 / 06 / 2012$.

VALADARES, J.; MOREIRA, M. A teoria da aprendizagem significativa: sua fundamentação e implementação. Coimbra: Edições Almedina, 2009.

VILLATE, J. E-learning na Universidade do Porto. Caso de Estudo: Física dos Sistemas Dinâmicos 2004/2005. II Workshop E-learning da Universidade do Porto, 2005. 
ZABALA, A. Planificação e desenvolvimento curricular na escola. Porto: ASA Editores, 1991.

A prática educativa. Como ensinar. Porto Alegre: Artmed, 1998. Os Pontos de Vista Didácticos. In ZABALA, A. O Construtivismo na Sala

de Aula. Porto: ASA Editores, 2001.

Enviado pelo autor em 19 de Junho de 2012.

Aprovado em 24 de Agosto de 2012. 